
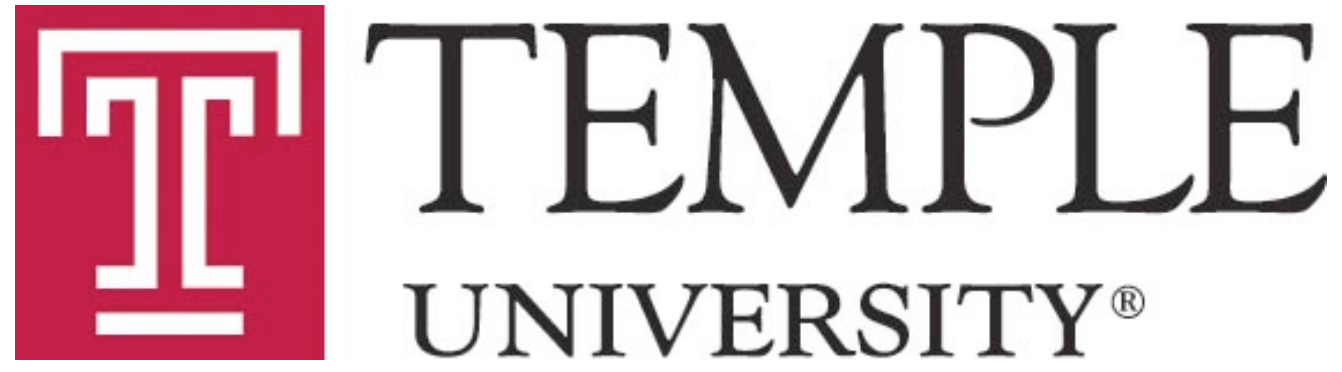

\title{
Offshoring and Occupational Specificity of Human Capital
}

by

Moritz Ritter

Department of Economics

DETU Working Paper 12-07

December 2012

1301 Cecil B. Moore Avenue, Philadelphia, PA 19122 http://www.cla.temple.edu/economics/research/working.htm 


\title{
Offshoring and Occupational Specificity of Human Capital*
}

\author{
Moritz Ritter ${ }^{\dagger}$
}

December 2012

\begin{abstract}
I document that workers in newly tradable service occupations possess more occupationspecific human capital and are more highly educated than workers in previously tradable occupations. Motivated by this observation, I develop a dynamic equilibrium model with labor market frictions and specific human capital to study the labor adjustment process after a trade shock. When calibrated to match the increase in U.S. trade between 1990 and 2010, the model suggests that (1) output increases immediately after a trade shock and converges quickly to the steady state; (2) labor market institutions play a larger role in the adjustment process than specific human capital; (3) the short run distributional effects are small if the labor market is flexible, even in the presence of specific human capital.
\end{abstract}

Keywords: Offshoring, Sectoral Labor Reallocation, Human Capital

JEL classification: E24, F16, J24, J62

\footnotetext{
*I am grateful to Shouyong Shi and Gueorgui Kambourov for their support and guidance. I have also benefited from discussions with Bernardo Blum, Andres Erosa, Peter Morrow, and Diego Restuccia. I received valuable comments from participants at various seminars and conferences. Financial support from Shouyong Shi's Bank of Canada Fellowship is gratefully acknowledged; the opinions expressed in this paper are my own and not those of the Bank of Canada. All remaining errors and shortcomings are mine.

${ }^{\dagger}$ Department of Economics, Temple University; e-mail: moritz@temple.edu
} 


\section{Introduction}

Technological progress has led to considerable changes in the organization of the production process - tasks traditionally completed in close physical proximity can now be spatially separated and carried out independently, thus spurring offshoring of intermediate processes or tasks. This development differs from past trade experiences as many newly tradable tasks are performed by high-skill service occupations. ${ }^{1}$ This has spurred a debate between two opposing viewpoints. One focuses on the long term gains and maintains that offshoring is productivity-enhancing. The other viewpoint stresses potential short term losses and warns about the disruptive effects of offshoring of high skill tasks.

In this paper, I speak to both sides of this debate. I first provide systematic evidence on the human capital possessed by workers employed in newly tradable service occupations. I document that these workers are on average much better educated $-70 \%$ of them have some education past high school - than the average worker in the U.S. labor force. They also accumulate significantly more occupation specific human capital, as indicated by almost 5 times higher returns to 10 years of occupational tenure than the average worker. ${ }^{2}$ Specific human capital is particularly relevant in the context of worker reallocation due to high-skill offshoring: were reallocated workers' human capital mostly general, their loss in productivity would likely be small, as workers would be able to apply most of their knowledge to new tasks. However, if workers who are exposed to increased offshoring have relatively more occupation specific human capital, they will be less willing to switch occupations since occupational switches bring about the destruction of these specific skills.

Motivated by this observation, I build on work by Kambourov (2009) and develop a small open economy model in which workers acquire human capital specific to the task they complete. ${ }^{3}$ Worker reallocation after a trade shock is not only costly because of the loss of any specific human capital, but also because of the risk of unemployment and the time it takes to find a suitable

\footnotetext{
${ }^{1}$ Grossman and Rossi-Hansberg (2008) coined the term "trade in tasks" for the fragmented global production process. In the context of trade in tasks, an occupation is the relevant labor market counterpart; a task is the output of an occupation.

${ }^{2}$ Kambourov and Manovskii (2009a) stress the importance of occupation specific human capital. They find that after controlling for occupational tenure, industry and employer tenure do not contribute significantly to wage growth, indicating that workers accumulate significant occupation-specific human capital.

${ }^{3}$ For brevity, "specific human capital" always denotes occupation specific human capital.
} 
new line of work. To capture these costs, the model features search frictions and a match-specific productivity shock. This structure allows the model to quantify the aggregate gains from trade, as well as the distributional effects from a trade shock. Specific human capital generates short run distributional effects which differ from the long run effects; the labor market frictions and the idiosyncratic productivity draw generate increased unemployment and job-shopping along the transition path.

After calibrating the model to match occupational turnover and the returns to occupational tenure observed in the U.S., I use the model to assess the labor market implications of the surge in trade in goods and services observed between 1990 and 2010. The dynamic nature of the model allows me to quantify not only the short run impact, but also the entire transition to the new steady state. The most important finding is that, even if the full magnitude of the trade shock is introduced at once (instead of the more staggered fashion observed in the data), the labor market impact of this "tradability revolution" is small. Almost $60 \%$ of the output gains are realized within one year and the transition is mostly concluded 5 years after the shock. As a result of this fast transition, the distributional effects are small as well: all workers see the net present value of their earnings increase immediately. In the long run, the competitive nature of the labor market leads to an equalization of expected earnings across all occupations. ${ }^{4}$

To further investigate the relative importance of specific human capital and labor market institutions, I conduct three counterfactual experiments. First, I introduce the increase in trade in goods and the increase in trade in services separately. Second, I simulate the response to the trade shock in an otherwise identical economy without specific human capital. Last, I increase the labor market frictions and decrease worker turnover relative to the baseline economy. Taken together, these experiments reveal that, in the case of the U.S., the flexible labor market plays a bigger role in the adjustment process than does the specific human capital of workers in high skill service occupations. With flexible labor markets, worker reallocation is fast. This dampens the adverse effects on the workers who stay in their occupation - typically the workers with the highest level

\footnotetext{
${ }^{4}$ This steady state result is comparable to the one in Mitra and Ranjan (2010), who incorporate search frictions into the Grossman and Rossi-Hansberg (2008) model of trade in tasks and show that offshoring can increase wages and lower unemployment if labor is mobile between sectors.
} 
of specific skills.

The relatively minor role of specific human capital can be explained by two facts: first, while workers in tradable service occupations have relatively much specific human capital, its loss is still small compared to the output loss associated with unemployment. Second, even in offshored service occupations, many workers have not yet acquired the narrow specific human capital that would be lost upon an occupation switch. In the model, as in the data, only about $40 \%$ of all workers spent enough time in an occupation to have acquired the highest level of specific human capital. The model predicts that these workers that in an occupation and retain their specific skills. In other words, the average specific human capital of switchers is lower than that of stayers.

\section{$1.1 \quad$ Related Literature}

The model used in this paper is similar to those in Kambourov (2009) and Cosar (2011). ${ }^{5}$ Both of these authors study the labor market in transition after a large trade shock. The focus of Kambourov (2009) is very different from the one in this paper, as it assesses the impact of labor market rigidities, such as firing costs, on the success of trade reforms in Latin America. As the goal of the present paper is to examine the impact of high skill offshoring on the U.S. economy, my model features substantially more worker heterogeneity that capture important features of the U.S. labor market. On the other hand, labor market frictions are modeled much more parsimoniously.

Just as the present paper, Cosar (2011) is interested the short run distributional effects of a trade liberalization. Differently from the results in this paper, the model predicts a substantially longer adjustment process and large distributional effects after the Brazilian trade reform of the early 1990s. The large distributional effects and the long transition arise primarily from Brazil's less flexible labor market and the author's attribution of the full wage gain over the life-cycle to specific experience. ${ }^{6}$

A strictly empirical approach to the employment consequences of offshore outsourcing in services

\footnotetext{
${ }^{5}$ An alternative approach to studying the dynamic nature of the reallocation of workers is followed in Artuc (2009), Artuc et al. (2010) and Dix-Carneiro (2011). These authors estimate structural dynamic models with switching costs between sectors to investigate the labor market response and the distributional effects of a trade reform. Also, earlier work on the dynamics of adjustment after a trade shock includes Mussa (1978) and Matsuyama (1992).

${ }^{6}$ In the calibration, workers' earnings increase by $41 \%$ in 5 years and $243 \%$ after 40 years of experience in a sector, leading to potentially very large earnings losses if a worker switches sectors.
} 
was taken by Amiti and Wei (2006) and Liu and Trefler (2008) who found that the employment effect is (still) small. Using Swedish data, Ekholm and Hakkala (2006) find a small negative effect for workers with intermediate levels of education.

This paper is also related to a recent literature that incorporates search models of the labor market into trade models. ${ }^{7}$ Labor market frictions give rise to equilibrium unemployment, which allows a consideration of the impact of trade on employment and of the distributional consequences of trade. In particular, Davidson et al. (2008) study the impact of offshoring of high skill employment on labor market outcomes and show that low skilled workers may benefit from high skill offshoring. Helpman and Itskhoki (2010) and Helpman et al. (2010) study models in which ex-ante identical workers are matched with heterogonous firms and investigate the relationship between labor market frictions and comparative advantage, unemployment, and inequality. This work on trade and the labor market is focused on steady state results, while the present paper explicitly models the time-consuming aspect of labor reallocation and skill acquisition and the resulting distributional effects.

\section{Evidence on Trade in Services and Specific Human Capital}

In order to discuss and analyze the labor market implications of offshoring, it is crucial to know which occupations are actually tradable. This is not a simple task, as trade in tasks is only at its beginning. One attempt has been made by Blinder (2009), who uses the Occupational Information Network $\left(\mathrm{O}^{*} \mathrm{NET}\right)$ database of job requirements and characteristics to describe occupations by their degree of offshorability. ${ }^{8}$ The author finds that between $22.2 \%$ and $29.0 \%$ of all jobs in 2004 were potentially offshorable. For the analysis presented in this section, I use the definition that leads to the lower bound, namely that all occupations with an index number above 50 are labelled

\footnotetext{
${ }^{7}$ This literature goes back to Davidson et al. (1999).

${ }^{8}$ Two other approaches for identifying tradable occupations have been proposed: by Liu and Trefler (2008), who link service import and export data (as reported by the Bureau of Economic Analysis, BEA) to the associated occupation, and Jensen and Kletzer (2005), who construct a geographic concentration index for occupations to classify tradable and non-tradable occupations. While both approaches give valuable insights into occupations potentially affected by trade in services, they both suffer from some important shortcomings. Using BEA data on currently traded services does not identify every potentially tradable occupation, since this type of trade is only in its early stages, whereas high geographic concentration of occupations can be an indication of tradability, but is not a necessary condition.
} 


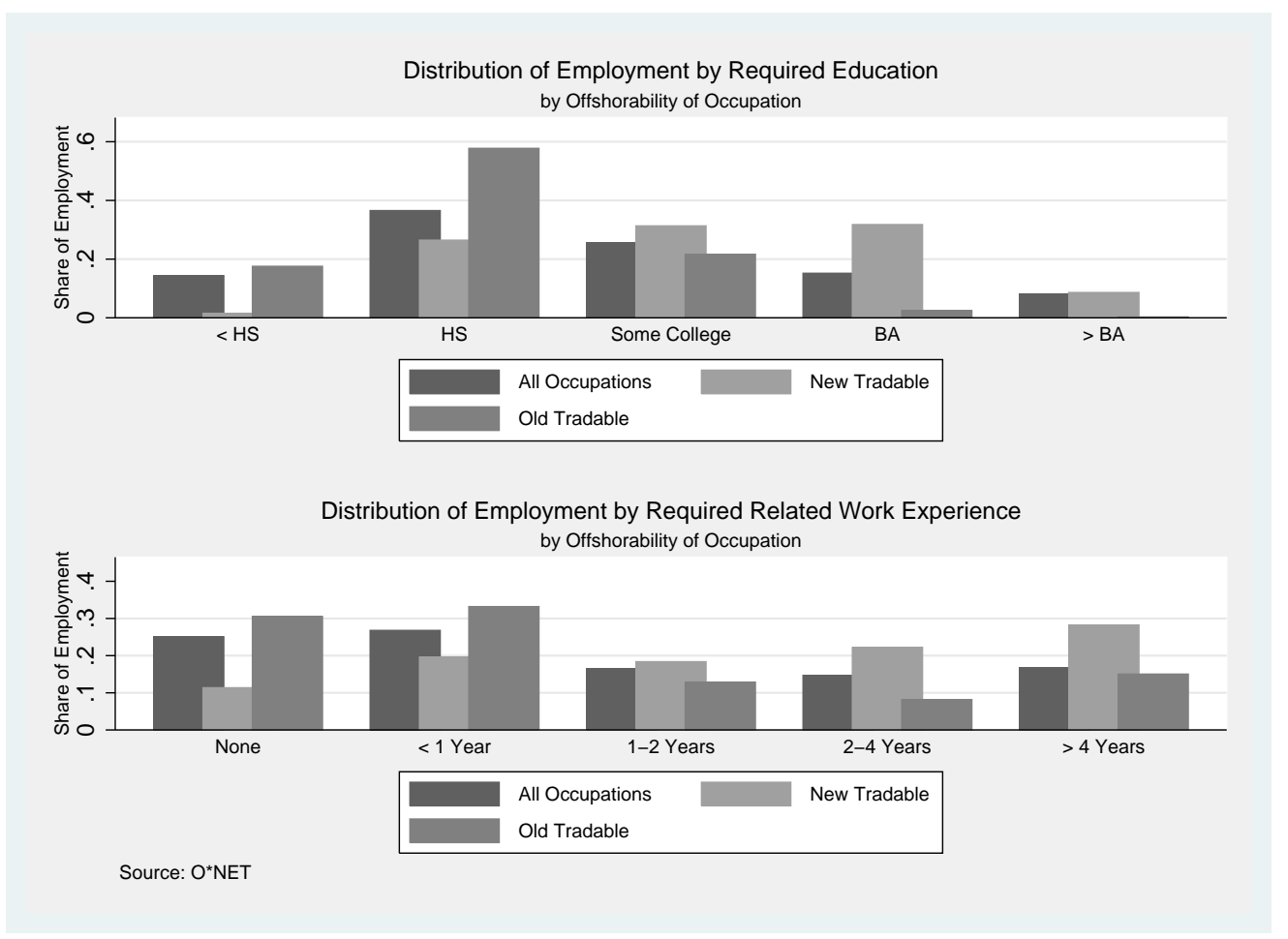

Figure 1: Differences in Required Education and Required Related Work Experience across Occupation Groups

as offshorable. ${ }^{9}$

Using the Blinder Index and additional data from $\mathrm{O}^{*} \mathrm{NET}$, Figure 1 shows that newly tradable service occupations (service occupations with a Blinder Index >50) differ from other occupations, in particular previously tradable production occupations, in both the level of education and the required related work experience. ${ }^{10}$ Workers employed in these occupations are almost twice as likely to have a college degree than the average worker and are almost never high school drop-outs; almost $70 \%$ of employment in newly tradeable service occupations has some education beyond high school. Workers employed in previously tradable occupations (goods producing occupations with a

\footnotetext{
${ }^{9}$ Blinder argues that this number is likely too restrictive, but also agrees that the upper bound of $29 \%$ is likely too aggressive. Since the lower bound is uncontroversial and involves a clear numeric cut-off, I will label occupations as offshorable if the Blinder Index exceeds 50.

${ }^{10}$ Education is based on the O*NET measure "Required Level of Education" and experience is based on the O*NET measure "Related Work Experience." "Related Work Experience" is part of the O*NET domain "Experience Requirements" for an occupation and measures the "Amount of related work experience required to get hired for the job." Such skills do not have to be acquired in that occupation, but are specific to an occupation or occupation groups. For example, "an accountant must complete four years of college and work for several years in accounting to be considered qualified," whereas "a teller would benefit from experience working directly with the public."
} 
Blinder Index $>50$ ), on the other hand, are almost exclusively high school graduates or drop-outs and almost never have a college degree.

While not quite as dramatic, the bottom chart shows that workers in tradable service occupations are much more likely to possess extensive related work experience than both the average worker and workers in production occupations. In particular, over $50 \%$ of all workers in newly tradable occupations require more than 4 years of related work experience, an indication that these workers likely acquire extensive specific human capital.

While this analysis provides preliminary evidence that workers in newly tradable service occupations possess both more general and more specific human capital than workers previously exposed to offshoring, it does not quantify the magnitude of these differences. However, for the potential implications of offshoring, it is paramount to know just how much general and specific human capital different workers accumulate. Only general human capital is transferrable between occupations in the face of an adverse trade shock, while specific human capital is not. ${ }^{11}$

In order to quantify these differences, I estimate returns to occupational tenure using a sample of males over 35 years of age from the 1996 and 2001 waves of the Survey of Income and Program Participation (SIPP) following the methodology in Kambourov and Manovskii (2009a). ${ }^{12}$ Table 1 presents the calculated returns to occupational tenure and, for comparison, the returns to overall labor market experience. For the full sample, I find that 5 years in the same occupation increases wages by about $3.7 \%$, and 10 years yield returns of $7.7 \%{ }^{13}$ Returns to overall labor market experience are noticeably higher at $15.7 \%$ and $25.5 \%$ for 5 and 10 years of potential experience, respectively.

The next three rows show important variations in returns to tenure across occupation groups. Production occupations - those occupations exposed to trade shocks in the past - have very similar

\footnotetext{
${ }^{11}$ It is important to keep in mind that the tasks offshorable occupations perform can potentially be traded and that, as a consequence, the U.S. will not necessarily become a net importer of higher skill tasks.

${ }^{12}$ See Appendix A for the details on the regression model and data.

${ }^{13}$ These returns are lower than those reported by Kambourov and Manovskii (2009a), who find using the PSID that workers over the age of 35 see an $8.1 \%$ wage increase after 5 years in an occupation. Several factors are potentially responsible, not least of which the fact that the returns to occupational tenure may have diminished since the 1980 s. If the wage increase is largest for workers switching employers and not occupations, and if these switches are correlated with exiting the sample, the high attrition rate in the SIPP will cause a downward bias in the returns to tenure as well.
} 
Table 1: Estimated Returns to Experience and Occupational Tenure

\begin{tabular}{|c|c|c|c|c|}
\hline & \multicolumn{2}{|c|}{$\begin{array}{c}\text { Returns to } \\
\text { Occupational Tenure }\end{array}$} & \multicolumn{2}{|c|}{$\begin{array}{l}\text { Returns to } \\
\text { Potential Experience }\end{array}$} \\
\hline & 5 years & 10 years & 5 years & 10 years \\
\hline All occupations & $\begin{array}{l}0.037 \\
(0.13)\end{array}$ & $\begin{array}{l}0.077 \\
(0.00)\end{array}$ & $\begin{array}{l}0.157 \\
(0.00)\end{array}$ & $\begin{array}{l}0.255 \\
(0.00)\end{array}$ \\
\hline New Tradable & $\begin{array}{l}0.158 \\
(0.00)\end{array}$ & $\begin{array}{l}0.265 \\
(0.00)\end{array}$ & $\begin{array}{l}0.109 \\
(0.00)\end{array}$ & $\begin{array}{l}0.165 \\
(0.00)\end{array}$ \\
\hline Old Tradable & $\begin{array}{l}0.028 \\
(0.47)\end{array}$ & $\begin{array}{c}0.0713 \\
(0.26)\end{array}$ & $\begin{array}{c}0.186 \\
(0.00)\end{array}$ & $\begin{array}{c}0.294 \\
(0.00)\end{array}$ \\
\hline All non-tradable & $\begin{array}{c}0.0243 \\
(0.14)\end{array}$ & $\begin{array}{l}0.055 \\
(0.01)\end{array}$ & $\begin{array}{l}0.158 \\
(0.00)\end{array}$ & $\begin{array}{l}0.260 \\
(0.00)\end{array}$ \\
\hline
\end{tabular}

Note: p-value in brackets.

"New tradable": Blinder Index>50 and SOC90 $\in(3,500)$; "Old tradable": Blinder Index $>50$ and SOC90€ (500,800)

returns to labor market experience to an average occupation, but do not offer significant returns to occupational tenure, suggesting that production workers do not accumulate much occupation specific human capital. Newly tradable service occupations, on the other hand, offer significantly higher returns to occupational tenure (at $15.8 \%$ and $26.5 \%$ for 5 and 10 years in an occupation, respectively), suggesting that workers in these occupations accumulate relatively larger amounts of specific human capital. Moreover, workers in these occupations, while highly educated, see significantly smaller returns to overall labor market experience (at least past age 35) than workers in non tradable occupations. ${ }^{14}$

These results are in line with the general perception that occupations previously exposed to offshoring boast less specific human capital and that workers in newly tradable occupations have "more to lose" should their line of work be offshored. Consequently, past trade experience might indeed not represent an accurate predictor for the potential labor market impact of trade in services - in the short run, the destruction of specific human capital might cause larger distributional effects and potentially significant losses to some groups of workers, even if the long run gains from comparative advantage are large. The following section describes a model of the labor market with

\footnotetext{
${ }^{14}$ These results are in line with Sullivan (2010) who finds in the NLSY that young workers in professional occupations have a $22.3 \%$ return to 5 years in an occupation, whereas operatives and laborers see no significant returns to occupational tenure.
} 
specific human capital that can be used to quantify the potential short run losses, the long run gains, and the transition between the short and the long runs after an increase in service trade.

\section{Model}

\subsection{Environment}

The economy is populated by a measure one of infinitely lived workers. Workers' preferences are linear in consumption and they discount the future at rate $\beta \in(0,1)$. Time is discrete and indexed by $t=0,1,2, \ldots$.

Production. A non-tradable final consumption good $Y$ is produced competitively using $N$ distinct intermediate inputs, called tasks:

$$
Y=\left[\sum_{i=1}^{N} y_{i}^{\rho}\right]^{\frac{1}{\rho}}
$$

where $\rho<1$ governs the elasticity of substitution between tasks.

For each task, there is a large number of producers. Labor is the only variable input in production; there is a also fixed factor for each task, to which each agent holds an equal share. The fixed factor is implied by the decreasing returns technology, which assures the task has a positive mass of workers, even in the presence of international competition. The representative task producer's technology is given by:

$$
y_{i}(z, l)=z_{i} l_{i}^{\alpha}, \alpha<1
$$

where $z_{i}$ is a time-invariant task-specific productivity parameter and $l_{i}$ is the total effective labor employed in producing task $i$.

A subset $M<N$ of the tasks are tradable; the economy is small relative to the rest of the world and so it takes the world market price as given. There are no trade costs, the domestic price for tradable tasks equals their world market price, $p_{i}=p_{i}^{w} \cdot{ }^{15}$

Perfect competition in the production of the final good implies that the price index for the final

\footnotetext{
${ }^{15}$ Note, that I not only abstract from trade costs but also from tariffs. Since tariffs are levied on goods and goods consists of many different tasks, it is not obvious how to think about a tariff on one particular task.
} 
good is given by

$$
P=\left(\sum_{i=1}^{N} p_{i}^{\frac{-\rho}{1-\rho}}\right)^{\frac{\rho-1}{\rho}}
$$

and the resulting demand for each task is given by

$$
y_{i}^{d}=\left(\frac{P}{p_{i}}\right)^{\frac{1}{1-\rho}} Y
$$

Labor Market. The labor market consists of many occupations where each occupation fulfills exactly one task. While there are search frictions between occupations (described below), the labor market within an occupation is competitive, so the real wage per effective unit of labor is the value of its marginal product:

$$
w_{i}=p_{i} \alpha z_{i} l_{i}^{\alpha-1}
$$

Workers are either employed in an occupation or are unemployed. At the beginning of the period, unemployed workers search for employment by applying to an occupation, i.e. search is directed. After applying, with probability $\phi$ the unemployed worker gets matched with the occupation to which she applied and draws her permanent worker-occupation specific productivity $s$ from some distribution $F(s)$. With probability $1-\phi$, she remains unemployed and receives a payoff $b$ from home production.

Workers can become unemployed by quitting or by exogenously separating. At the beginning of each period, an employed worker decides whether to remain in the current occupation and retain the current productivity draw $s$, or become unemployed and search for a new line of work. At the end of each period (except the first period in the occupation), a worker may become separated from the occupation exogenously at rate $\delta$. Workers who separate from their occupation may begin applying to a new one immediately. The timing assumptions imply that a worker will remain in an occupation for at least one period.

Human Capital. Human capital is occupation specific and is accumulated through learning-by- 


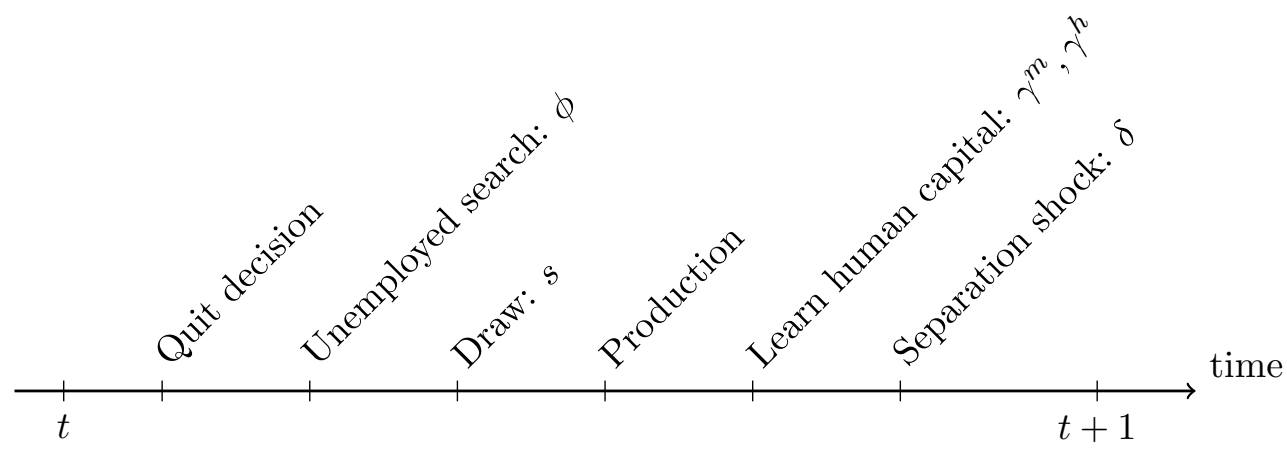

Figure 2: Time-line of events within a period.

doing. There are three levels of occupation-specific skills. A worker enters the occupation as an unskilled worker and, at the end of each period (except the first one), the worker may acquire the specific human capital necessary to become a medium skilled worker. The arrival rate of the skill shock for an unskilled worker is $\gamma^{m}$. Similarly, a medium skilled worker becomes high-skilled at rate $\gamma^{h}$.

The increase in productivity upon becoming skilled varies between occupations, but within an occupation all agents experience the same relative increase in their productivity. While an unskilled worker has $s$ units of productive time each period, a medium skilled worker has $a_{i}^{m} s$ and a high skilled worker has $a_{i}^{h} s$, with $1<a_{i}^{m}<a_{i}^{h}$. After becoming skilled, a worker remains skilled until she leaves the occupation. The time-line is depicted in Figure 2.

\subsection{The Worker's Problem}

Employed Worker. A worker employed in occupation $i$ at the beginning of each period faces the decision whether to quit and search for a new line of work or remain employed in the current occupation. Let $\mu$ denote the distribution of workers across occupations, idiosyncratic productivities, and occupation specific human capital at the beginning of a period and $U(\mu)$ the associated value of searching. Then the Bellman equation for a high skilled worker with productivity $s$ in 
occupation $i$ is given by: ${ }^{16}$

$$
\begin{aligned}
V_{i}^{h}(s, \mu) & =\max \left\{J_{i}^{h}(s, \mu) ; U(\mu)\right\} \\
\text { with } \quad J_{i}^{h}(s, \mu) & =s a_{i}^{h} w_{i}+\beta\left((1-\delta) V_{i}^{h}\left(s, \mu^{\prime}\right)+\delta U\left(\mu^{\prime}\right)\right) .
\end{aligned}
$$

Similarly, the Bellman equations for medium and unskilled workers are given by:

$$
\begin{aligned}
V_{i}^{m}(s, \mu) & =\max \left\{J_{i}^{m}(s, \mu) ; U(\mu)\right\}, \\
\text { with } \quad J_{i}^{m}(s, \mu) & =s a_{i}^{m} w_{i}+\beta\left((1-\delta)\left(\gamma^{h} V_{i}^{h}\left(s, \mu^{\prime}\right)+\left(1-\gamma^{h}\right) V_{i}^{m}\left(s, \mu^{\prime}\right)\right)+\delta U\left(\mu^{\prime}\right)\right), \\
\text { and } \quad V_{i}^{u}(s, \mu) & =\max \left\{J_{i}^{u}(s, \mu) ; U(\mu)\right\}, \\
\text { with } \quad J_{i}^{u}(s, \mu) & =s w_{i}+\beta\left((1-\delta)\left(\gamma^{m} V_{i}^{m}\left(s, \mu^{\prime}\right)+\left(1-\gamma^{m}\right) V_{i}^{u}\left(s, \mu^{\prime}\right)\right)+\delta U\left(\mu^{\prime}\right)\right),
\end{aligned}
$$

respectively. Each worker takes the value of search, $U$, and the future values of $V^{u}, V^{m}$ and $V^{h}$ as given. The values of staying in an occupation are increasing in the idiosyncratic productivity draw $s$. Therefore, the worker's optimal quitting decision can be described by a simple reservation productivity strategy: if the productivity draw exceeds the reservation level, the worker remains in the occupation, otherwise the worker leaves and searches for a better match. Thus, a worker of type $j \in\{u, m, h\}$ will leave occupation $i$ if

$$
J_{i}^{j}(s, \mu)<U(\mu)
$$

and the optimal quitting policy can be described by an indicator function:

$$
g_{i}^{j}(s, \mu)= \begin{cases}1 & \text { if }(10) \text { holds } \\ 0 & \text { otherwise }\end{cases}
$$

In a stationary equilibrium in which the distribution of workers across occupations, productivities, and skills is time invariant and all prices and wages are constant, workers employed in each occu-

\footnotetext{
${ }^{16}$ Note that prices for non-traded tasks and hence wages depend on the full distribution of workers $\mu$, but I will suppress that in the notation below.
} 
pation will be either temporary or permanent. Temporary workers are those who entered at the beginning of the current period, received a low productivity draw, and will search again in the next period; permanent workers will remain and only leave after an exogenous separation.

Unemployed Worker. An unemployed worker who is currently searching applies to the occupation that offers the highest expected value of applying. Hence, the Bellman equation for unemployed workers is given by:

$$
U(\mu)=\max _{i \in N}\left\{\phi E_{s}\left(J_{i}^{1}(s, \mu)\right)+(1-\phi)\left(b+\beta U\left(\mu^{\prime}\right)\right)\right\}
$$

where $E_{s}$ denotes the expectation operator over the possible idiosyncratic productivities $s$ and $J_{i}^{1}(s, \mu)$ denotes the value of entering the occupation $i$ with draw $s$,

$$
J_{i}^{1}(s, \mu)=s w_{i}+\beta V_{i}^{u}\left(s, \mu^{\prime}\right) .
$$

This takes into account that a worker who just entered the occupation may not acquire specific human capital and is not subject to exogenous separation at the end of the first period.

Search is directed, so any occupation that wishes to attract applicants must offer them the same expected value. If the value of applying to occupation $i$ is less than for other occupations, no worker will apply and employment in that occupation will shrink due to the exogenous separation and quitting. As is common in the directed search literature, I focus on the symmetric mixedstrategy equilibrium in which identical workers use identical, mixed application strategies.

Employment Dynamics. During the production stage, workers are either employed or unemployed. Employed workers vary by idiosyncratic productivity and their specific human capital. Between two production stages, workers may endogenously or exogenously leave an occupation and may acquire specific human capital. Let $g^{A}(\mu)=\left(g_{1}^{A}(\mu), g_{2}^{A}(\mu), \ldots, g_{N}^{A}(\mu)\right)$ denote the policy function describing the optimal mixed application strategy for workers and $A(\mu)$ the total number of applicants. Thus, the total number of workers applying to occupation $i$ is $A_{i}(\mu)=g_{i}^{A}(\mu) A(\mu)$. 
The resulting law of motion for the beginning of the period distribution of workers is given by

$$
\begin{aligned}
\mu_{i}^{h^{\prime}} & =(1-\delta)\left(g^{h}(s, \mu) \mu_{i}^{h}+\gamma^{h} g^{m}(s, \mu) \mu_{i}^{m}\right) \\
\mu_{i}^{m^{\prime}} & =(1-\delta)\left(g^{m}(s, \mu)\left(1-\gamma^{h}\right) \mu_{i}^{m}+\gamma^{m} g^{u}(s, \mu) \mu_{i}^{u}\right) \\
\mu_{i}^{u^{\prime}} & =(1-\delta)\left(1-\gamma^{m}\right) g^{u}(s, \mu) \mu_{i}^{u}+\phi A_{i}(\mu) d F(s) .
\end{aligned}
$$

\subsection{Equilibrium}

A competitive equilibrium for given world prices $\left\{p_{i}^{w}\right\}_{i \in M}$ consists of

- value functions for workers $\left\{V_{i}^{j}(s, \mu), J_{i}^{j}(s, \mu), J_{i}^{1}(s, \mu)\right\}_{i \in N, j \in\{u, m, h\}}$,

- associated policy functions $\left\{g_{i}^{j}(s, \mu), g_{i}^{A}(\mu)\right\}_{i \in N, j \in\{u, m, h\}}$ '

- the value of searching $U(\mu)$,

- distribution of workers across occupations and skill levels $\mu$,

- domestic supply of and demand for intermediate tasks $\left\{y_{i}^{S}, y_{i}^{D}\right\}_{i \in N}$ and final output $Y$,

- prices and wages $\left\{p_{i}, w_{i}\right\}_{i \in N}$ for each task and an aggregate price index $P$,

such that:

1. Given $U(\mu)$, prices, and wages, workers' value functions and associated policy functions maximize workers' individual utility.

2. The distribution of workers across sectors and skill levels follows (14) - (16).

3. Wages are determined competitively.

4. The labor market in each occupation clears and aggregate feasibility is satisfied.

5. The final good market and the task markets clear.

6. Trade is balanced: $0=\sum_{i \in M} p_{i}^{w}\left(y_{i}^{S}-y_{i}^{D}\right)$. 


\subsection{Discussion of Modelling Choices}

Directed Search. Directed search is a natural modeling choice when it comes to occupations or lines of work. An unemployed worker may send his resume to many different employers, but typically will limit herself to a smaller set of possible occupations. Furthermore, I am interested in the worker relocation resulting from a large, permanent shock and it is likely agents will specifically target occupations with a positive shock and avoid those with a negative one. In steady state, agents are indifferent between all occupations, so they would be willing to apply for positions in any occupation; only along the transition path is the assumption of directed search critical. The model contains an element of undirected search as well - the worker-occupation specific productivity shock introduces a layer of randomness akin to random search.

Human Capital. Workers are ex ante identical in the model, but there are three sources of ex post heterogeneity which capture the essential barriers to worker reallocation. First, search frictions imply that workers will not immediately find a new job upon leaving the old occupation; finding a job takes time. Second, the idiosyncratic match productivity captures that not every job is a good match. A worker may go through several spells of short employment until she finds a permanent match. Lastly, occupation specific human capital is acquired over time, so a skilled worker is more reluctant to leave her current line of work. General human capital, by definition, is transferrable across occupations and since the focus of the analysis is the transition path, I choose to omit general human capital for simplicity.

Tasks, not Goods. After a trade shock to an industry (good), workers in that industry may be forced to find employment in a different industry. For some workers, this industry switch will be accompanied by little change in the tasks they fulfill - the duties of a secretary or truck driver are mostly independent of the industry in which they are employed. For other workers, however, the industry switch will involve a switch in their occupation as well. As Kambourov and Manovskii (2009a) have shown, workers accumulate much more occupation-specific human capital than industry-specific (or employer-specific) human capital. In studying the labor market implications of international trade, it is therefore natural to model trade as trade in tasks. This is particularly the case when we think about the implications of high skill service trade. As shown in 
Section 2, workers performing offshorable service tasks accumulate much more occupation specific human capital than the production workers who were forced to switch occupations as a result of previous trade shocks.

Small Open Economy. The reason for modelling the U.S. (the focus of the quantitative analysis below) as a small open economy is twofold. Naturally, a small open economy is much easier to model then a two country model with endogenous prices for all tasks. However, given that I am interested in the labor market impact, this simplification is much more innocuous than it appears at first. The goal of this paper is to provide a model whose labor market structure captures key features in the data - a model which can be calibrated to quantify the impact of trade in tasks on key labor market outcomes. As such, it does not aim to explain the actual pattern of trade, but rather takes it as given. In the quantitative analysis, the relative prices are chosen to match observed trade flows and ultimately the analysis is agnostic as to how that that price is determined.

\section{Quantitative Analysis of U.S. Trade Experience}

In this section, I calibrate the model to the U.S. economy at the advent of the surge in service trade (1990) and then subject the economy to a trade shock that generates the magnitude of trade in goods and services observed in 2010. In order to obtain the greatest possible short run effect, the full magnitude of the trade shock is assumed to hit the economy at once. This is meant to capture a worst case scenario since it involves the most worker relocation and hence the largest destruction of specific human capital. Assuming the claims that U.S. workers are hurt by trade in high skill services are correct, this scenario would have to capture any such losses. In the long run, after reallocation and retraining, the gains from exploiting one's comparative advantage will dominate; the presumed losses stem from increased unemployment and the destruction of specific human capital in the short run. Were trade introduced very gradually, none or only a few skilled workers would switch occupations and minimal destruction of human capital would occur, which implies that there would be no short term distributional effects. In other words, losses resulting from the one-time shock presented in this section represent the upper bound on the potential short run cost of increased offshoring. 
Table 2: Parameters common across occupations

\begin{tabular}{ccccccc}
\hline$\beta$ & $\delta$ & $\phi$ & $\gamma^{m}$ & $\gamma^{h}$ & $\rho$ & $\alpha$ \\
\hline 0.96 & 0.114 & 0.768 & 0.25 & 0.2 & -1.5 & 0.68 \\
\hline
\end{tabular}

Table 3: Parameters differing across occupations

\begin{tabular}{l|c|cccc}
\hline & employment share '90 & $a^{m}$ & $a^{h}$ & $\sigma$ & $z$ \\
\hline tradable occupations & & & & & \\
high skill services & $3.6 \%$ & 1.198 & 1.340 & 13.2 & 0.82 \\
low skill services & $5.6 \%$ & 1.092 & 1.126 & 18.4 & 0.94 \\
production and manual labor & $9.6 \%$ & 1.030 & 1.072 & 22.0 & 0.99 \\
non-tradable occupations & & & & & \\
high skill services & $36.0 \%$ & 1.049 & 1.094 & 21.5 & 0.98 \\
low skill services and manual labor & $45.2 \%$ & 1.026 & 1.055 & 22.8 & 1 \\
\hline
\end{tabular}

\subsection{Parameterization}

The model period is chosen to be one year, as the focus of the analysis is the long-run transition from one steady state to another, rather than movements at a business cycle frequency. This is also consistent with the modelling choice of directed search, as discussed above. Consistent with the annual frequency, I set the discount factor at $\beta=0.96$.

The parameterized economy consists of 500 occupations, grouped into five large occupation categories: tradable high and low specific skill services, non-tradable high and low specific skill services and tradeable production occupations. ${ }^{17}$ All occupations within a category are assumed to be identical, i.e. they have identical specific human capital processes and specific productivity distributions.

The parameters of the specific human capital process, $\left(a^{m}, a^{h}, \gamma^{m}, \gamma^{h}\right)$, are chosen to match the occupational tenure profile for occupations in each occupation category. The typical occupationtenure profile is concave and levels off after about ten years. I therefore set $a^{m}$ to match the average return to occupational tenure for an occupation within each category after 5 years and $a^{h}$ to match the return after 10 years; $\gamma^{m}$ and $\gamma^{h}$ are set such that a worker is expected to obtain the

\footnotetext{
${ }^{17}$ The cut-off for tradablility is a Blinder Index above 50. The high and low skill grouping follows Census groupings, executive, professional and technical occupations are labelled "high skill services" and the remaining service occupations make up "low skill services". All other occupations are either production (previously tradable) or manual labor occupations.
} 


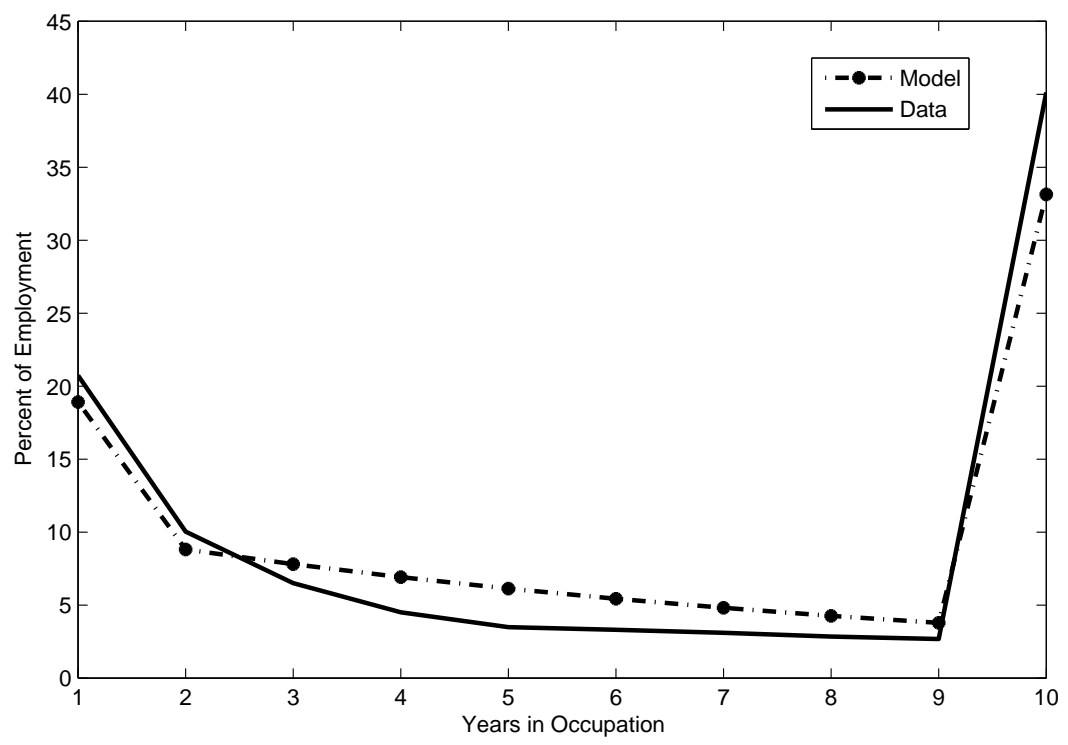

Figure 3: Distribution of Occupational Tenure

medium level after 5 and the high level of specific human capital after 10 years in the occupation (see Appendix A for further details).

The distribution of match-specific productivity shocks is assumed to be Pareto with a minimum of 1 . As proposed by Menzio and Shi (2011), the shape parameter of the distribution $\sigma$ can be set to match the fraction of workers in the first year of their occupational tenure. The probability of leaving an occupation after accumulating more than one year of tenure, $\delta$, is chosen to match an average occupational tenure of 9.5 years at the time of an occupation switch (conditional on the switch occurring after year 1), consistent with the data from the 1996 wave of the SIPP. Figure 3 depicts how well the combination of $\sigma$ and $\delta$ allows the model to match the occupational tenure distribution in the 1996 wave of the SIPP. Note that, while $\delta$ is the same across occupation groups, $\sigma$ varies across groups because the reservation productivity differs with the amount of specific human capital that can be acquired. Lastly, the probability of receiving an offer, $\phi$, is set to generate an unemployment rate of $5.6 \%$ (the average rate in 1990) and the value of home production, $b$, is set at a standard 60 percent replacement rate.

Calibrating the parameters of the production process is less straightforward due to the lack of data available at the occupation level. For example, the labor share of output within an industry can 
easily be calculated from national accounts data, but there is no comparable information available for occupations, as the output of an occupation on its own is not easily measured. I therefore use the same curvature parameter of the task production function for all occupation groups and, as in Kambourov and Manovskii (2009b), I set it to match an average labor share in the economy of 0.68. The productivity parameter for each task, $z_{i}$, is chosen such that all occupations have the same employment level in the initial 1990 steady state, with the productivity in non-tradable low skill services normalized to 1 . The number of occupations in each category is then set such that each category's share of total employment matches that category's share in the 1990 census. ${ }^{18}$

Finally, the elasticity of substitution between tasks, governed by $\rho$, is set to match the labor demand elasticity (elasticity of wages with respect to employment) at the 2-digit occupation level (22 groups) of 0.5 , which implies $\rho=-1.5$, i.e. tasks are more complementary than Cobb-Douglas; see Appendix B for details. The appendix also presents a robustness check with a higher elasticity of substitution between tasks, which shows that the choice of $\rho$ has consequences for the magnitude of the gains from trade but a relatively minor effect on the labor market implications of a trade shock. A list of all parameters and targets is provided in Tables 2. and 3.

\subsection{Response to Increased Offshoring}

After computing the initial steady state, I perturb the world prices to match the increase in trade between 1990 and 2010, where 2010 is treated as the new steady state. As discussed in the introduction to this section, after obtaining the new set of prices, I shock the initial 1990 steady state by allowing the economy to trade at this new set of world prices. The relevant trade data is shown in Table 4: between 1990 and 2010, imports of private business services increased from $0.38 \%$ to $1.24 \%$ of GDP and exports of services increased from $0.69 \%$ to $1.72 \%$ of GDP. ${ }^{19}$ During the same time period, imports of goods increased by $5.5 \%$ of GDP to $16.1 \%$ of GDP, while exports of goods rose by $3.4 \%$ of GDP to $12.7 \%$ of GDP. In the quantitative exercise, I match this increase in trade

\footnotetext{
${ }^{18}$ This approach was chosen over matching each of the 500 occupations' employment share because it drastically reduces the number of parameters. For the quantitative exercise, the total number of workers exposed to trade and their level of human capital is crucial, not their occupation assignment.

${ }^{19}$ In line with previous work on service offshoring, I consider trade in services as trade reported in the BEA category "other private services", i.e. total private-sector services excluding transportation services, royalties and license fees.
} 
Table 4: Trade Flows as Fraction of GDP

\begin{tabular}{lcccc}
\hline & \multicolumn{2}{c}{ Goods } & \multicolumn{2}{c}{ Other Private Services } \\
& Imports & Exports & Imports & Exports \\
\hline 1990 & $10.62 \%$ & $9.22 \%$ & $0.38 \%$ & $0.69 \%$ \\
2010 & $16.09 \%$ & $12.65 \%$ & $1.24 \%$ & $1.72 \%$ \\
$\Delta$ & $5.47 \%$ & $3.43 \%$ & $0.86 \%$ & $1.03 \%$ \\
\hline
\end{tabular}

Source: Bureau of Economic Analysis

in services and exports of goods, but because trade is required to be balanced in the model, the increase in imports of goods is somewhat smaller than in the data.

In the data, we observe the trade of goods and services but, unfortunately, we do not observe the exact task composition of these goods. In 1990, production workers made up $70.4 \%$ of employment in manufacturing and received $58.7 \%$ of wages paid in manufacturing; weighted by the industry level increase in imports and exports between 1990 and 2005, production workers receive 54.5\% of wages paid. ${ }^{20}$ I therefore assign $54.5 \%$ of the increase in goods trade to production occupations and the remainder to non-tradable occupations (e.g. management, transportation). For trade in services, based on data presented in Koncz-Bruner and Flatness (2011), I assign $75 \%$ of trade in services to tradable high and $25 \%$ to tradable low skill services. As with the assumption that all trade is introduced at once, this can be regarded as a worst case scenario. Most likely, some of the value added embedded in these goods is created by tasks labelled as non-tradable, but by attributing all of the value to tradable tasks, the possible negative short run impact is maximized.

The experiment is broken into three parts. First, in the main simulation, I match all trade flows. Second, I separate the trade in goods from the trade in services and introduce each of them separately to assess the role of specific human capital in the transition. Last, I conduct two counterfactual experiments with an identical trade shock in economies without specific human capital and with a less flexible labor market, respectively. The computation of the transition paths is described in Appendix C.

\footnotetext{
${ }^{20}$ Employment and payroll data from the NBER-CES Manufacturing Industry Database, Bartelsman et al. (1990) and trade data from Schott (2008).
} 

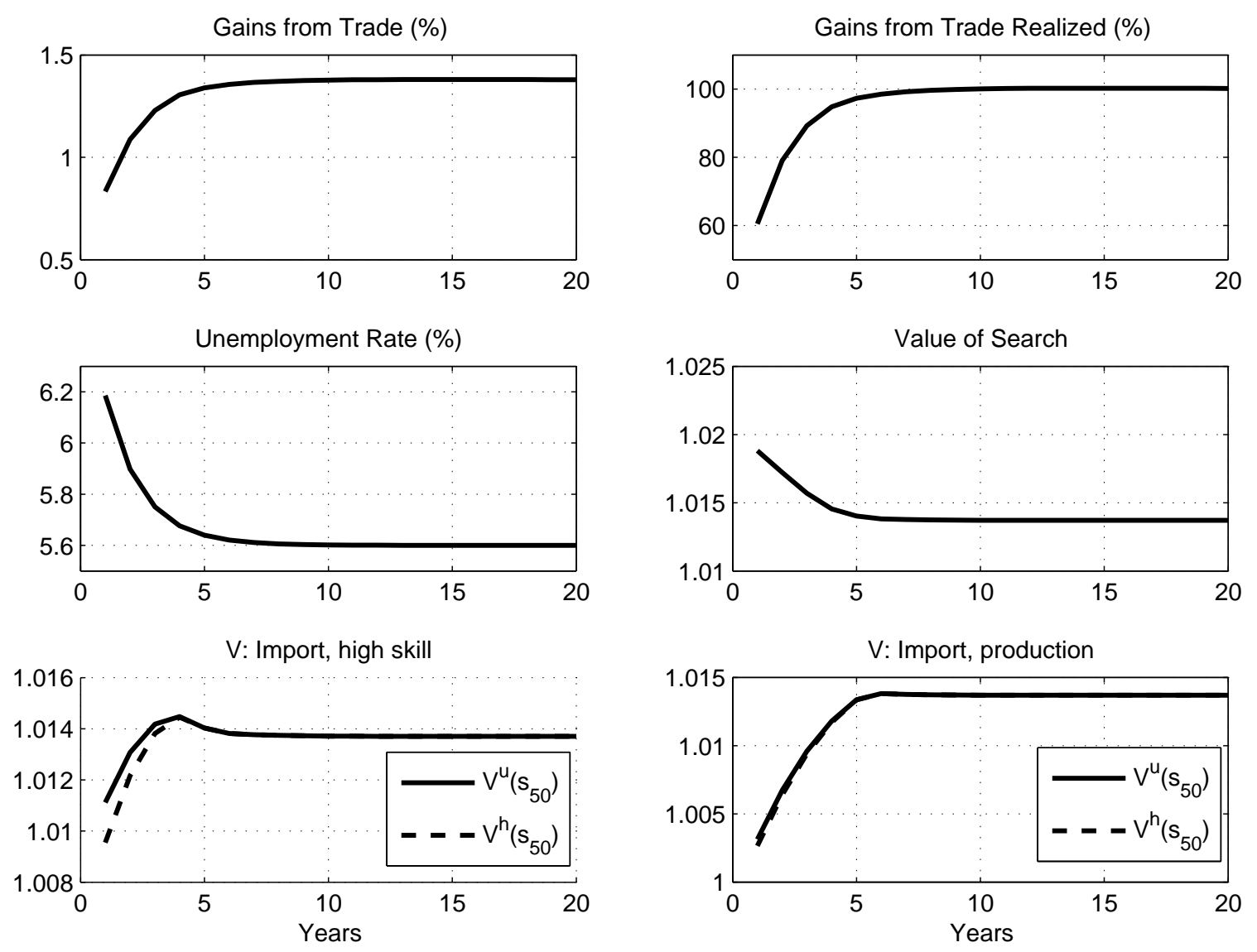

Figure 4: Response to Offshoring Shock. Note: bottom row value functions are that of the worker with median productivity.

\subsubsection{Baseline Trade Shock}

Matching the trade flows in 2010, production of the final consumption good is increased by about $1.4 \%$ in the new stationary equilibrium compared to the 1990 steady state. ${ }^{21}$ Introducing the full change in relative prices at once, output increases by $0.84 \%$ (60\% of the steady state increase) in the first year after the shock and converges quickly; after 4 years, more than $90 \%$ of the transition is complete and after 10 years the economy is fully converged (see top row of Figure 4).

The distribution of the gains from trade crucially depends on the time horizon. As can been seen in the fourth plot in Figure 4, workers employed in occupations with a positive shock or non-

\footnotetext{
${ }^{21}$ For comparison, Broda and Weinstain (2006) estimates the gains from trade between 1972 and 2001 to be 2.6 percent of GDP and Ossa (2012) recently estimated that the move from autarky to the 2005 levels of trade in goods increased real income by $6.4 \%$ in the U.S. if a constant elasticity of aggregate trade flows with respect to trade costs is used across all industries.
} 
tradable occupations initially see the present value of expected earnings increase by almost $2 \%$, which in turn increases the value of search by the same percentage (recall that the value of search is equal to the expected value of being an unskilled worker in occupations that attract a positive number of applicants). ${ }^{22}$ On the other hand, workers employed in offshored occupations see their expected present value of earnings increase by less than $0.5 \%$ in production occupations and about $1 \%$ in high skill service occupations (last row of Figure 4). However, within 5 years, the competitive forces of the labor market equalize the gains. Workers direct their search to occupations, which ensures that the expected value of being an unskilled worker is equally increased by $1.4 \%$ across all occupations.

To better understand these dynamics, it is instructive to inspect the reallocation of workers across occupations. Upon realization of the shock, holding the initial distribution of employment fixed, the value of the marginal product of labor (and hence the wage paid) falls in offshored and increases in inshored occupations, triggering the initial reallocation of workers. The value of applying to the inshored occupations exceeds the value of applying to offshored occupations and offshored occupations do not attract any applicants. Furthermore, because of the shift in relative wages, a worker who was previously indifferent between staying and quitting will now leave an offshored occupation. The reservation productivity in offshored occupations increases and many unskilled and some skilled workers leave offshored occupations. This leads to a sharp drop in employment in offshored and a corresponding increase in employment in inshored occupations, as can be seen in the left column of Figure 5.

The left column of Figure 5 also shows that employment in offshored occupations remains above the new steady state level for several years, while employment in inshored occupations is below the new steady state for several years. Because of labor market frictions and the specific human capital, the initial labor market adjustment is only partial. Some of the workers leaving the offshored occupations do not find new employment immediately and unemployment initially increases (third graph in Figure 4). Moreover, workers with good occupation matches and specific human capital remain in offshored occupations rather than search, maintaining an above steady

\footnotetext{
${ }^{22}$ Because of this relationship, only the value of search is shown; the value functions in all inshored occupations display the same percentage increase as the value of search.
} 
(a) Total employment relative to initial steady state
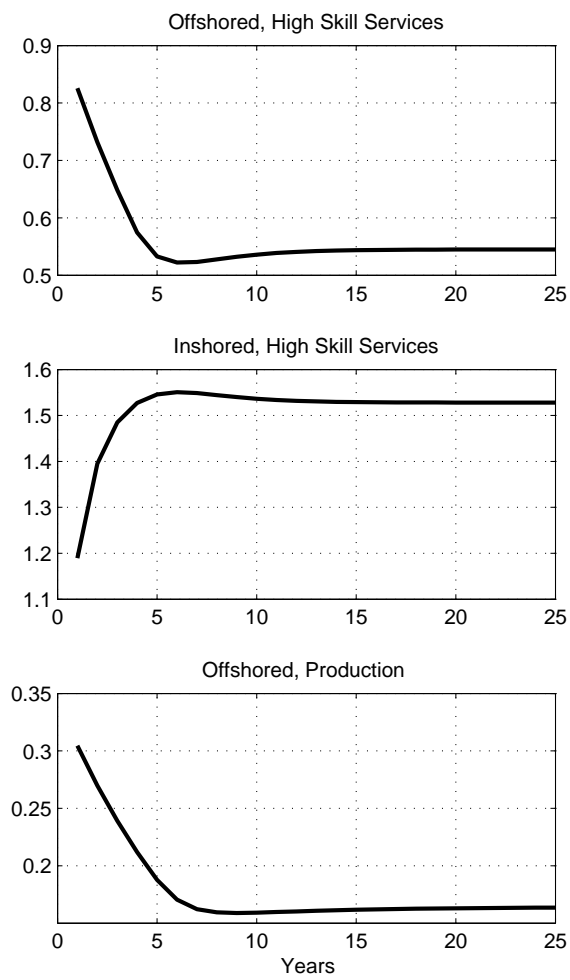

(b) Fraction of workers with highest level of specific human capital
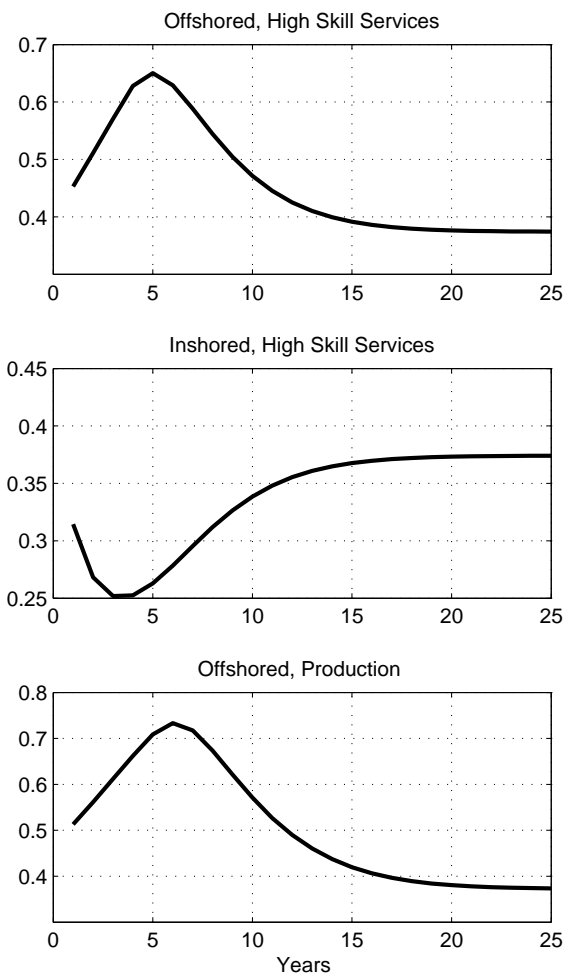

Figure 5: Employment Response to Offshoring Shock for Selected Occupation Groups.

state level of employment in these occupations for several years.

After the first year, some of the applicants to inshored occupations become permanent workers and increase the effective labor supply in those occupations, which lowers the wage rate per unit of labor. The labor supply in the offshored occupations is further reduced through exogenous separation, which somewhat increases the wage rate. Thus, the value of searching relative to the value of staying permanently in offshored occupations decreases; permanent workers (skilled and unskilled) only leave their occupation in the first period after the negative shock. However, the value of applying to the inshored occupations still exceeds that of the offshored; just as in the first period, only the inshored occupations receive applicants in the second period. Over time, the effective labor force in the offshored occupations is further reduced through exogenous separation, while it keeps growing in the inshored - both through entry and acquisition of specific human capital. Eventually, the value of applying to all occupations is equalized again and both receive a 
positive number of applicants. The gains from trade are now equally distributed across occupations.

At the beginning of the transition, average productivity in offshored occupation increases and continues to increase in subsequent years as no new applicants enter while the remaining workforce continues to acquire specific skills. The opposite is true for inshored occupations; because of the inflow of new workers, the average productivity falls and the fraction of high skilled workers decreases for several years before slowly converging back to the steady state (see right column of Figure 5). Note that this productivity effect also implies that the average income falls by less than the marginal product of labor in offshored occupations and increases by less than the marginal product of labor in inshored occupations. This has potential implications for empirical investigations on the effect of offshoring; cross-sectional data on workers' earnings might understate the true impact of offshoring on income since they ignore this selection effect.

Returning to the dynamics of output, the initial increase in output is a result of the economy exploiting its comparative advantage, paired with the reallocation of workers from the offshored to the inshored occupation. All but the most productive unskilled and also some of the less productive high skill workers are leaving the offshored occupation and apply to the inshored occupation, as discussed above. However, since some of these workers do not receive an offer in the first year and others receive a low productivity draw, aggregate output in the first year increases by less than the new steady state level. By the end of the third year, most workers who switched receive a productivity draw above the reservation level, i.e. they find a good occupation match in one of the inshored occupations and unemployment and output have almost converged to the new steady state. The remaining transition is workers re-accumulating specific skills. However, relative to the reduction in unemployment, specific human capital adds very little - the majority of the transition process is completed by that time.

\subsubsection{Specific Human Capital vs. Labor Market Institutions}

While the above analysis indicates that trade in services is not much different from trade in goods, it might be that the destruction of human capital from service trade is masked by the gains from trade in production occupations. To further investigate the importance of specific human capital, 

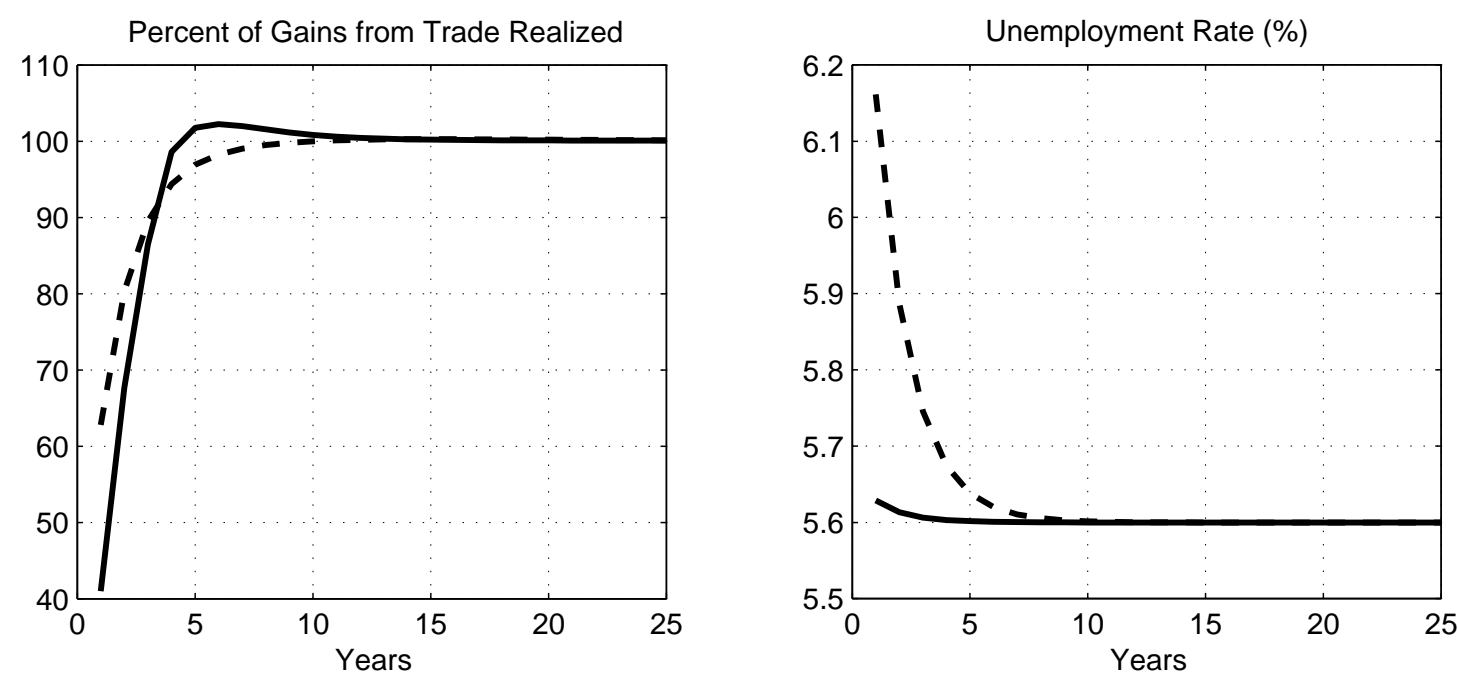

Figure 6: Comparison of trade shocks: service trade only (solid line) vs. production trade only (dashed line).

I introduce the observed increases of trade in services and trade in goods separately. Workers in both sets of occupations face the same labor market frictions, but workers in service occupations acquire substantially more specific human capital.

Figure 6 shows that specific human capital slows down the transition. In the case of service trade, unemployment increases only slightly; for high-skill occupations, most of the reallocation of workers comes via the natural turnover as fewer workers separate voluntarily in the initial period after the shock. As result, in the short run, the realization of the gains from trade in services is slower than the realization of the gains from trade in goods. However, even with service trade, the gains from trade in the short run are positive and the economy mostly converges after 3-4 years. Moreover, because there is very little excess unemployment, the increase in the average productivity in offshored occupation after the trade shock leads to a small overshooting in output in the case of service trade.

To contrast this with the role of labor market institutions, I simulate the behavior of two alternative economies. The first economy is identical to the baseline economy, except that workers do not acquire any specific human capital, i.e. $a_{m}=a_{h}=0$ whereas the second economy is characterized by a less flexible labor market. In the model, labor market institutions are captured by $\phi$, the probability of receiving an offer if searching in the current period (frictions). Also, one 
can think of $\delta$, the probability of exogenous separation, as capturing labor market institutions such as the imposition of firing costs. For this experiment, I increase $\phi$ to match an unemployment rate of $8.4 \%$, which represents an increase of $2.8 \%$ relative to the baseline calibration (the difference between the U.S. and Western Europe in the early 1990s, see Wasmer, 2006). I also reduce $\delta$ to match an average occupation tenure at separation after the first year of 12 years (instead of 9.5 years). All other calibration targets, as well as the parameters set outside the model, remain the same..$^{23}$

These changes leave the steady state increase in output unchanged - in steady state, aggregate output increases by $1.4 \%$, the same as in the baseline calibration. Figure 7 (a) (left column) shows that specific human capital has played a relatively minor role in the experience of the U.S. since 1990. The most noticeable difference is in the distributional effects, which are more muted. In the absence of any specific human capital, there is more immediate reallocation of workers and hence the value if search overshoots by less and the value of staying in an offshored occupation undershoots by less than in the baseline calibration. The increase in turnover has two counteracting effects on output: it increases unemployment in the short run, but also reallocates more workers toward the comparative advantage occupations right upon impact. Taken together, these two effects almost cancel out and the short run effect on output is nearly identical to the baseline economy. After that, output converges at the same rate as in the baseline economy with specific human capital.

On the other hand, Figure 7(b) (right column) shows that labor market institutions are crucial for the speed of convergence to steady state. This can best be seen by comparing the path of aggregate output for the economy with more frictions (solid line) to that generated by the same trade shock in the baseline economy (dashed line): in the economy with more frictions, output increases less in the first period and grows more slowly over the next few years; convergence takes an extra 1.5-2 years.

The reason for the smaller increase in output in the first period is the lower quit-rate in occupations that received a negative shock in the first period, which leads to lower labor relocation towards occupations which received the positive shock. In the initial period after the shock, employment

\footnotetext{
${ }^{23}$ One could argue that such an environment is likely to produce higher levels of specific human capital (e.g. Wasmer, 2006); an exercise such as calibrating the model to continental Europe is left for future research.
} 

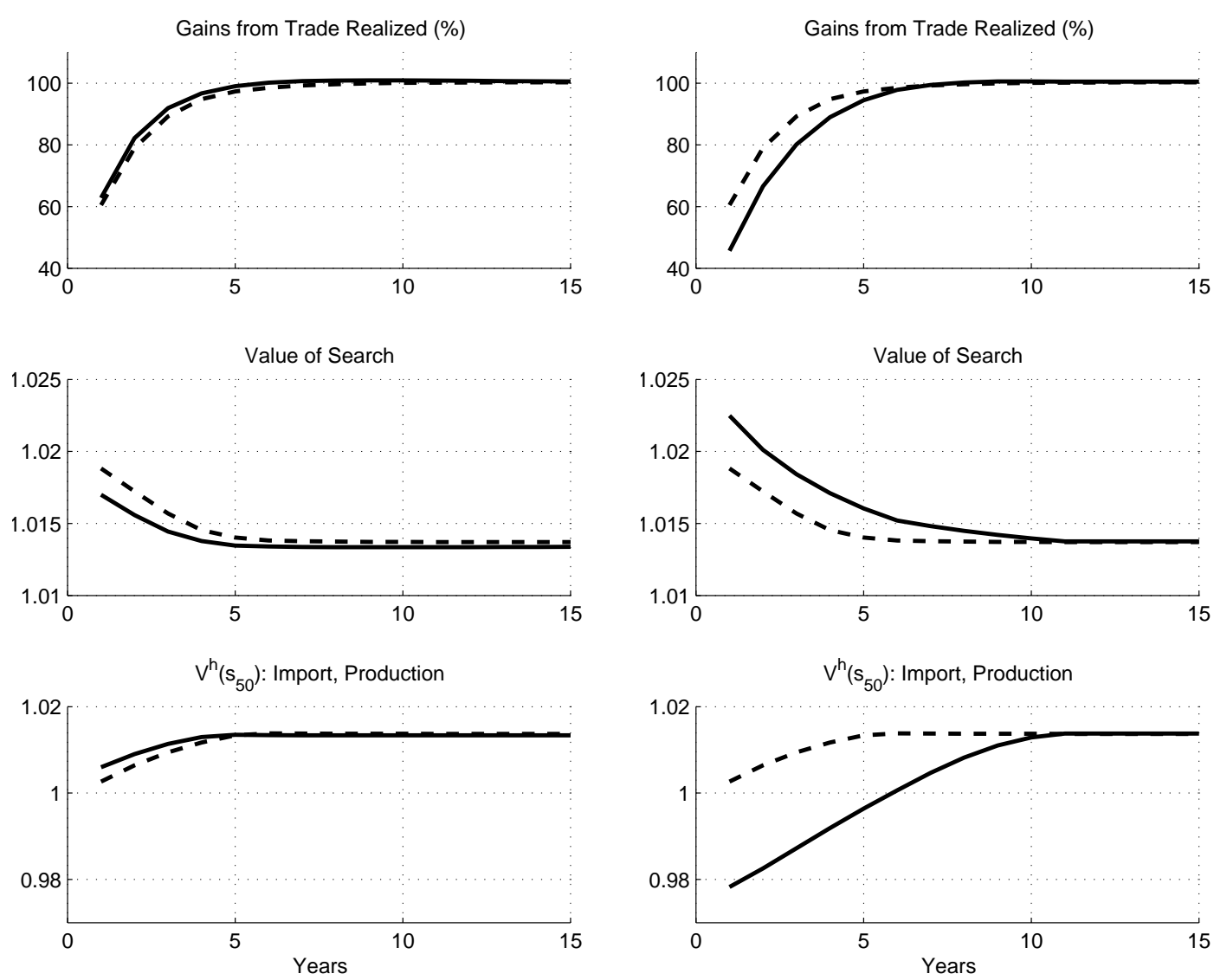

(a) Comparison baseline calibration (dashed line) to economy without specific human capital (solid line).

(b) Comparison baseline calibration (dashed line) to economy with increased labor market frictions (solid line).

Figure 7: loyment Response to Offshoring Shock for Selected Occupation Groups in Alternative Economies.

Note: values and employment are relative to pre-shock steady state.

in the production occupations drops to about $45 \%$ of the initial steady state, compared to $30 \%$ in the baseline calibration and similarly for other occupations with a negative shock. Because fewer workers leave the import-competing occupations in the economy with larger labor market frictions in the first period after the shock, the exporting occupations see their employment increase by less. Workers are less inclined to leave their current occupations for two reasons. First, because of the lower job-finding rate, workers are more reluctant to leave their current occupation and search. Second, the value of specific human capital and of a good match is increased because of the lower separation rate. In subsequent periods, the output growth is further slowed by the lower exogenous 
separation - a worker who decided not to quit in the first period will remain in the offshored occupation until her occupation-match is destroyed. As a consequence, these workers remain in the offshored occupation for a longer period of time and make the economy with larger frictions behave more like a specific factors model.

Similarly to a specific factors model, the distributional effects of the trade shock are more pronounced in the economy with frictions because of the reduced worker reallocation. The value of search (identical for occupations with a positive shock) and human capital specific to an inshored occupation overshoot the steady state gains from trade more strongly in the economy with frictions, while workers with human capital specific to offshored occupations experience a larger loss. These results indicate that the flexible labor market plays a bigger role than the specific human capital at least for the magnitude of trade experienced in the U.S..

\section{Conclusion}

In this paper, I document that workers in newly tradable service occupations are more highly educated and possess more occupation-specific human capital than workers in previously tradable occupations. Building on this insight, I develop a model of a small-open economy in which labor market frictions and occupation-specific human capital play a key role in determining labor reallocation after a trade shock. The calibrated model is then used to assess the implications of increased trade in high skill services on the U.S. labor market between 1990 and 2010. The findings suggest that labor market institutions are a more important determinant of the short run dynamics than is the specificity of human capital. While specific human capital takes several years to reacquire, the magnitude of specific human capital is small relative to the output loss associated with unemployment and both are small relative to the aggregate gains from trade.

In an economy with flexible labor markets, workers with little specific human capital switch into occupations that received a positive trade shock, while the most productive workers (i.e. those with a good occupation match and much specific human capital) decide to stay in their occupation. This reallocation assures that the economy can exploit its comparative advantage, while at the same time it dampens the adverse effect on the skilled workers who stay in their occupations. In 
an economy with more severe labor market frictions and institutions limiting workers turnover, workers are more reluctant to switch occupations and the distributional effects are stronger as a result - workers in offshored occupations potentially see the present value of their incomes fall.

These results suggest that trade in high skill services is not much different than trade in goods. As with all trade, there are long run gains from exploiting one's comparative advantage. Contrary to popular belief, the short run cost stemming from labor reallocation and the destruction from good matches and specific human capital is small, even in the case of high skill service trade.

\section{APPENDIX A: Estimation of Specific Human Capital}

\section{Data}

The dataset of individual employment profiles used to estimate the returns to tenure presented in Section 2 is taken from the 1996 and 2001 waves of the Survey of Income and Program Participation (SIPP). The advantage of using the SIPP is the relatively large sample size in comparison with other panel data sets, which unfortunately results in a trade-off with relatively short panel length (4 and 3 years, respectively). The size of the dataset allows an estimation of the returns despite the relatively short sample and ensures a justified departure from using data from the 1980s and early 1990s, which is advantageous for three reasons. Firstly, many of the occupations now exposed to offshoring were neither fully developed nor common some 20 years ago; secondly, since there is no reason to believe that the returns to tenure are constant over time even as the returns to schooling have evolved, including earlier years of data would likely not produce estimates most relevant to current discussions on offshoring. Finally - and most importantly - the SIPP data was collected at a monthly frequency, with individuals responding to one interview every four months. This allows a much more reliable identification of job switchers - something that posed a significant challenge in previous studies using the Panel Study of Income Dynamics, PSID (Brown and Light, 1992), and the National Longitudinal Survey of Youth, NLSY.

Respondents in the SIPP are asked to give the start- and end- dates for every job, allowing me to obtain very reliable information on employer tenure and thus circumvent the issue of initialization 
of employer tenure at the beginning of the sample. In the very first interview, the respondent is asked how long she has been working in the current "line of work", which allows me to initialize occupational tenure as well. The SIPP provides no information on initial industry tenure, therefore I initialize industry tenure with occupation tenure at the beginning of the sample. Finally, since I do not observe an individual from the time she enters the labor market, I have no information on her actual acquired overall work experience. However, the SIPP provides very detailed information on schooling, so I can use potential experience - age less 6 less number of years of schooling - as a proxy for actual experience. To minimize the resulting bias, I restrict the sample to male full-time workers.

In each interview, the respondent is asked retrospectively about the past four months, and the responses are recorded for each month individually. The individual reports employer, occupation and industry classifications, hours worked, and total income. She also reports start- and end-dates for each job, which allows me to identify job switches and calculate employer tenure with relatively high precision. ${ }^{24}$ Following Kambourov and Manovskii (2009a), occupation and industry switches are only coded as "true" switches if they coincide with employer switches. Using this convention, $19.6 \%$ of participants switch their employers at least once per 12 months; $14.4 \%$ switch occupations, and $13.6 \%$ industries. These shares are somewhat lower than their PSID equivalents in Kambourov and Manovskii (2009a) and Sullivan (2010). Some of this can be explained with my restriction of the sample to individuals age 35 and older in order to mitigate potential biases from job-shopping (see below). Furthermore, the SIPP suffers from sample attrition; if workers who lose their jobs are more likely to leave the sample, this could explain fewer job, occupation, and industry switches in this sample.

\footnotetext{
${ }^{24}$ Nevertheless, there is a significant seam bias in the data; more switches happen "at the seam", or between interviews (e.g. between months 4 and 5, 8 and 9) than within interviews (e.g. between months 1 and 2,2 and 3 ). However, since I am not interested in estimating a hazard function, this bias is a minor issue and causes only a small error when calculating tenure - at the most 3 months.
} 


\section{Estimation and Results}

Following the empirical literature measuring returns to tenure ${ }^{25} \mathrm{I}$ estimate the following earnings equation:

$$
\begin{aligned}
\ln w_{i j m n t}= & \beta_{1} \text { EmpTen }_{i j t}+\beta_{2} \text { OccTen }_{\text {imt }} \\
& \quad+\beta_{3} \text { IndTen }_{\text {int }}+\beta_{4} \text { WorkExp } \text { Ex }_{i t}+\alpha X_{i j m n t}+\kappa_{i j m n t}
\end{aligned}
$$

where $w_{i j m n t}$ is the real hourly wage of worker $i$ at employer $j$ in occupation $m$ and industry $n$. WorkExp denotes overall labor market experience, while EmpTen, OccTen and IndTen denote tenure with the current employer, occupation and industry, respectively. $X$ is a set of observables which influence wages independently of tenure: gender, race, educational attainment, union status, firm size, 1-digit industry and occupation affiliation, and state and year fixed effects. $\kappa_{i j m n t}$ an error term decomposed as follows:

$$
\kappa_{i j m n t}=\mu_{i}+\lambda_{i j}+\xi_{i m}+\nu_{i n}+\epsilon_{i t}
$$

where $\mu_{i}$ is an individual-specific component and $\lambda_{i j}, \xi_{i m}, \nu_{i n}$ are job-match, occupation-match, and industry-match components, respectively. These unobserved components pose a potentially serious challenge in estimating the returns to tenure consistently; workers with good employer (occupation/ industry) matches, for example, may be more likely to have remained with their employer (occupation/ industry) longer while at the same time receiving a higher wage due to the excellent match quality. Estimating (A-1) using Ordinary Least Squares will therefore likely result in upward-biased estimates. Thus, I follow the approach developed by Altonji and Shakotko (1987), which has been widely adopted in the literature and employ an instrumental variable estimation strategy.

The standard instruments for experience and the three tenure variables are the deviations of experience/tenure for individual $i$ from the individual's mean experience/tenure in the observed

\footnotetext{
${ }^{25}$ See, among others: Altonji and Shakotko (1987), Neal (1995), Altonji and Williams (2005), and Kambourov and Manovskii (2009a).
} 
spell. If $T_{i t}$ is the current tenure of worker $i$, the corresponding instrument is $\widetilde{T_{i t}}=\left(T_{i t}-\overline{T_{i}}\right)$, where $\overline{T_{i}}$ is the average tenure of individual $i$ in the current spell. The instruments are orthogonal to their respective match components by construction but unfortunately not necessarily orthogonal to the other match components; e.g. the instrument for occupation tenure, OccTen $\widetilde{\text { imt }}=$ $\left(O c c T e n_{i m t}-\overline{O c c T e n_{i m}}\right)$, could potentially be still be correlated with the job-match unobserved effect $\lambda_{i j}$. For example, an individual with a good employer, but bad occupation match might be less inclined to switch occupations than an otherwise identical individual with a bad job match because switching occupations most likely also results in losing the good employer match. However, Kambourov and Manovskii (2009a) argue that the possible correlations between the match components and the tenure variables are more likely a source of a downward bias then an upward bias. Furthermore, to mitigate the effect from job-shopping, the most likely source of a systematic bias, I restrict my sample to workers age 35 and older since most of the job-shopping is concentrated early in workers' careers.

For the estimation, I group occupations into 5 major categories. Occupations are labeled as tradeable if the Blinder Index exceeds 50. Within tradable occupations, I classify managerial, professional and technical occupations (1990 Census code of less than 240) as "high skill services," sales, administrative and other service occupations (1990 Census code between 240 and 470) are classified as "low skill services." The remaining tradable occupations are previously tradable production occupations. For non-tradable occupations, I label occupations as "high skill services" as above and the remaining occupations are relatively low skill services and manual labor.

The results are listed in Table A-1. The relative magnitude of the returns is as expected, with the exception of high skill non-tradable occupations. This is most likely because a significant number of workers in this bin are in managerial occupations, a group for which industry tenure might be more important than occupation tenure (Sullivan, 2010). 
Table A-1: Returns to Occupation Tenure, by Occupation Groups

\begin{tabular}{ccc}
\hline & 5 years & 10 years \\
\hline tradable occupations & & \\
high skill services & 0.1984 & 0.3402 \\
& $(0.000)$ & $(0.001)$ \\
low skill services & 0.0918 & 0.1267 \\
& $(0.228)$ & $(0.312)$ \\
production and manual labor & 0.0301 & 0.0723 \\
& $(0.437)$ & $(0.258)$ \\
non-tradable occupations & & \\
high skill services & 0.0494 & 0.0940 \\
& $(0.193)$ & $(0.095)$ \\
low skill services and manual labor & 0.0261 & 0.0550 \\
& $(0.160)$ & $(0.042)$ \\
\hline
\end{tabular}

Note: p-value in brackets.

\section{APPENDIX B: Elasticity of Substitution between Tasks}

Unfortunately, differently from goods, tasks and their prices are not directly observable in the data, which makes a direct estimation of the elasticity of substitution between tasks impossible. However, in the model, the tight link between occupations and tasks (each occupation fulfills exactly one task) allows identification of the elasticity of substitution between tasks from the labor demand elasticity at the occupation level.

Market clearing for each task requires

$$
z_{i} l_{i}^{\alpha}=\left(\frac{P}{p_{i}}\right)^{\frac{1}{1-\rho}} Y .
$$

Using that workers are paid the value of their marginal product, (3), and the market clearing conditions for tasks, the effective labor supply in each occupation satisfies

$$
l_{i}^{\frac{1-\alpha \rho}{1-\rho}}=\left(\frac{\alpha P}{w_{i}}\right)^{\frac{1}{1-\rho}} z_{i}^{\frac{\rho}{1-\rho}} Y .
$$


This is the basis for the following regression equation:

$$
\log l_{i t}=\eta \log w_{i t}+\Lambda_{i}+\Lambda_{t}+\epsilon_{i t}
$$

where $\eta \equiv \frac{-1}{1-\alpha \rho}$ and $\Lambda_{i}$ and $\Lambda_{t}$ are occupation and time fixed effects.

I estimate this equation using total employment and average wages for 22 large occupation groups from the 2000 - 2005 BLS Occupational Employment Statistics. ${ }^{26}$ This sample was chosen because 5 years of data offer sufficient variation in wages and employment to identify $\eta$ (elasticity of employment with respect to wages) while also being short enough to be able to make the assumption of constant $z_{i}$ (using a long panel would raise issues such as technological change increasing the demand for some tasks). I restrict attention to 2-digit occupations (22 occupation groups) to minimize spurious changes due to misclassification and measurement errors that arise when using 3-digit occupations.

Regressing log total employment on log average wages and a set of time and occupation dummies, I obtain an estimated elasticity between employment and wages of $\hat{\eta}=-0.496$ (s.e. 0.197). Using the calibrated value of $\alpha=0.68$, this implies $\hat{\rho}=-1.49$ with a standard error of 1.177 (Delta-method).

However, to the extent that this estimate in not very precise and that there is more substitutability between more narrow occupations, this estimate likely represents an upper bound. For this reason, I conduct a robustness check with a higher degree of substitutability between tasks, using $\rho=-0.75$. Figure 8 shows that increasing the elasticity of substitution between tasks decreases the gains from trade somewhat but has little effect on the behavior of the economy. Most noticeably, unemployment increases only to $6 \%$ (as opposed to $6.2 \%$ in the baseline) but the workers' value functions display a similar patters of over- and undershooting in the short run.

\footnotetext{
${ }^{26}$ The first year for which this data is available is 1997 , but the occupation classification system was changed in 2000 .
} 

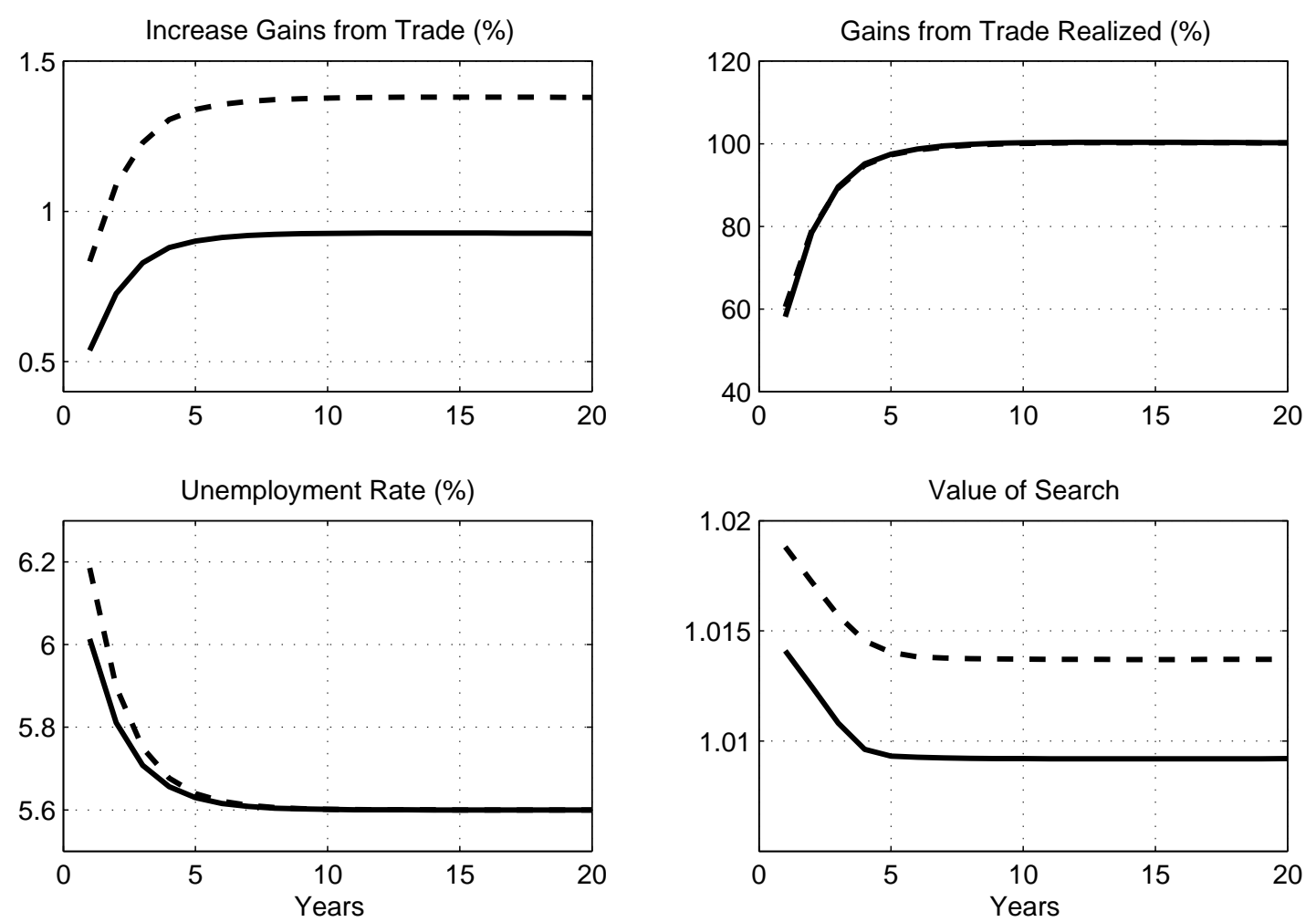

Figure 8: Response to Offshoring Shock with $\rho=-0.75$ (solid line); dashed line: baseline calibration. 


\section{APPENDIX C: Algorithm to Compute Transition Path}

1. Compute autarky and trade steady states.

2. Set the number of periods for the transition path to a sufficiently large number, $T=50$.

3. Guess the time path of all value functions $\left\{\tilde{V}_{i t}^{j}, \tilde{U}_{t}\right\}$ and the reservation productivities $\left\{\tilde{\hat{s}}_{i t}^{j}\right\}$.

4. Starting in period $t=1$, using the guess for next period's values and reservation productivities and the distribution of workers across occupations and skill levels, solve for the workers' optimal quitting and search decisions: $\left\{\hat{s}_{i t}^{j}, g_{i t}^{A}\right\}$.

5. Compute the implied wages and distribution of workers: $\left\{w_{i t}^{j}, \mu_{t}\right\}$.

6. Using the implied distribution from (5.), repeat steps (4.) and (5.) forward in time until period $T-1$.

7. Starting from period $T-1$, moving backward in time, use wages and reservation productivities to compute workers' updated value functions: $\left\{V_{i t}^{j}, U_{t}\right\}$.

8. If $\tilde{U}_{t} \approx U_{t}, \forall t$ and $\tilde{V}_{i t}^{j} \approx V_{i t}^{j} \forall i, j, t$, convergence. If not, set $\tilde{V}_{i t}^{j}=V_{i t}^{j}$ and $\tilde{U}_{t}=U_{t}$ and repeat (4.)-(7.).

\section{References}

[1] Altonji, Joseph and Robert Shakotko (1987): "Do Wages Rise with Seniority?" Review of Economic Studies, Vol. 54, pp. 437-459.

[2] Altonji, Joseph and Nicolas Williams (2005): "Do Wages Rise with Job Seniority? A Reassessment." Industrial and Labor Relations Review, Vol. 58(3), pp. 370-397.

[3] Amiti, Mary and Shang-Jin Wei (2006): "Service Offshoring, Productivity and Employment: Evidence from the US." CEPR Discussion Papers No. 5475.

[4] Artuc, Erhan (2009): "Intergenerational Effects of Trade Liberalization." Mimeo, Koc University.

[5] Artuc, Erhan, Shubham Chaudhuri and John McLaren (2010): "Trade Shocks and Labor Adjustment: A Structural Empirical Approach." American Economic Review, Vol. 100(3), pp. 1008-45. 
[6] Bartelsman, Eric J., Randy A. Becker and Wayne B. Gray (2000): "The NBER-CES Manufacturing Industry Database." NBER Technical Working Paper 205.

[7] Broda, Christian and David E. Weinstein (2006): "Globalization and the Gains from Variety." The Quarterly Journal of Economics, Vol. 121(2), pp. 541-585.

[8] Blinder, Alan (2009): "How Many U.S. Jobs Might Be Offshorable." World Economics, Vol. 10(2), pp. 41-78.

[9] Brown, James N. and Audrey Light (1992): "Interpreting Panel Data on Job Tenure." Journal of Labor Economics, Vol. 10(3), pp. 219-257.

[10] Cosar, Kerem (2011): "Adjusting to Trade Liberalization: Reallocation and Labor Market Policies." Mimeo, University of Chicago.

[11] Davidson, Carl, Lawrence Martin and Steven Matusz (1999): "Trade and Search Generated Unemployment." Journal of International Economics, Vol. 48, pp. 271-299.

[12] Davidson, Carl, Steven Matusz and Andrei Shevchenko (2008): "Outsourcing Peter To Pay Paul: High-Skill Expectations And Low-Skill Wages With Imperfect Labor Markets." Macroeconomic Dynamics, Vol. 12, pp. 463-479.

[13] Dix-Carneiro, Rafael (2011): "Trade Liberalization and Labor Market Dynamics." Mimeo, University of Maryland.

[14] Ekholm, Karolina and Katariina Hakkala (2006): "The Effect of Offshoring on Labor Demand: Evidence from Sweden." CEPR Working Paper No. 5648.

[15] Grossman, Gene and Esteban Rossi-Hansberg (2008): "Trade in Tasks: A Simple Theory of Offshoring." American Economic Review, Vol. 98(5), pp. 1978-1997.

[16] Helpman, Elhanan and Oleg Itskhoki (2010): "Labor Market Rigidities, Trade and Unemployment." Review of Economic Studies, vol. 77(3), pp. 1100-1137.

[17] Helpman, Elhanan, Oleg Itskhoki and Stephen J. Redding (2010): "Inequality and Unemployment in a Global Economy." Econometrica, vol. 78(4), pp 1239-1283.

[18] Jensen, J. Bradford and Lori G. Kletzer (2005): "Tradable Services: Understanding the Scope and Impact of Services Offshoring." In Brookings Trade Forum 2005 (ed. Lael Brainard and Susan M. Collins). The Brookings Institution: Washington D.C..

[19] Kambourov, Gueorgui (2009): "Labor Market Regulations and the Sectoral Reallocation of Workers: The Case of Trade Reforms." Review of Economic Studies, Vol. 76(4), pp. 1321-1358.

[20] Kambourov, Gueorgui and Iourii Manovskii (2009a): "Occupational Specificity of Human Capital." International Economic Review, Vol. 50(1), pp. 63-115. 
[21] Kambourov, Gueorgui and Iourii Manovskii (2009b): "Occupational Mobility and Wage Inequality." Review of Economic Studies, Vol.76(2), pp. 731-759.

[22] Koncz-Bruner, Jennifer and Anne Flatness (2011): "U.S. International Services: Cross-Border Trade in 2010 and Services Supplied Through Affiliates in 2009." Survey of Current Business, Vol. 91(10), pp. 13-31.

[23] Liu, Runjuan and Daniel Trefler (2008): "Much Ado About Nothing: American Jobs and the Rise of Service Outsourcing to China and India." NBER Working Paper No. 14061.

[24] Matsuyama, Kiminori (1992): "A Simple Model of Sectoral Adjustment." The Review of Economic Studies, Vol. 59(2), pp. 375-387.

[25] Menzio, Guido and Shouyong Shi (2011): "Efficient Search on the Job and the Business Cycle." Journal of Political Economy, Vol. 119(3), pp. 468-510.

[26] Mitra, Devashish and Priya Ranjan (2010): "Offshoring and Unemployment." Journal of International Economics, Vol. 81(2), pp. 219-229,

[27] Mussa, Michael (1978): "Dynamic Adjustment in the Heckscher-Ohlin-Samuelson Model." Journal of Political Economy, Vol. 86(5), pp. 775-91.

[28] Neal, Derek (1995): "Industry-Specific Human Capital: Evidence from Displaced Workers." Journal of Labor Economics, Vol. 13(40), pp. 653-677.

[29] Ossa, Ralph (2012): "Why Trade Matters After All.”NBER Working Paper, No. 18113.

[30] Schott, Peter K. (2008): "The relative sophistication of Chinese exports." Economic Policy, Vol. 23(53), pp. 5-49.

[31] Sullivan, Paul (2010): "Empirical Evidence on Occupation and Industry Specific Human Capital." Labour Economics, vol. 17(3), pp. 567-580.

[32] Wasmer, Etienne (2006): "Interpreting Europe-US Labor Market Differences : the Specificity of Human Capital Investments." American Economic Review, Vol. 96(3), pp. 811-831. 